REVISTA ECONOMÍA

Vol. 67, N. ${ }^{\circ}$ I05 (mayo 20I5), 29-57.

\title{
POSNEOLIBERALISMO Y URBANIZACIÓN PLANETARIA EN LA AMAZONÍA ECUATORIANA
}

\author{
JAPHY WILSON, MANUEL BAYÓN, HENAR DIEZ \\ Instituto de Altos Estudios Nacionales
}

Recepción manuscrito: 03 de marzo de $2015^{1}$

Aceptación versión final: 15 de abril de 2015

\begin{abstract}
RESUMEN Este artículo explora las posibilidades y limitaciones del posneoliberalismo bajo las condiciones de la urbanización planetaria. Conceptualiza la urbanización planetaria como la tendencia hacia la subsunción real del espacio al capital en una escala global, a través de la cual el capital se fortalece como una forma abstracta de dominación. Critica la agenda neoestructuralista de "competitividad sistémica» y su influencia en el proyecto posneoliberal en América Latina, argumentando que se tiende a fortalecer el capital como sujeto. Se enfoca en la urbanización de la Amazonía ecuatoriana, desagregamos la subsunción real del espacio en tres dimensiones: territorio, naturaleza y vida cotidiana.
\end{abstract}

palabras Clave Posneoliberalismo, Amazonía ecuatoriana, urbanización, capital.

ABSTRACT This article explores the possibilities and limitations of postneoliberalism under the conditions of planetary development. Planetary urbanization conceptualized as the tendency towards real subsumption of space to capital on a global scale, through which capital is strengthened as an abstract form of domination. Criticizes the neo-structuralist agenda «systemic competitiveness» and its influence in the post-neoliberal project in Latin America, arguing that it tends to strengthen the capital as a subject. It focuses on the development of the Ecuadorian Amazon, disaggregate the real subsumption of space in three dimensions: territory, nature and everyday life.

KEY WORDS Posneoliberalism, Ecuadorian Amazon, urbanization, capital.

CODIFICACIÓN JEL N9, N76, O2O.

\section{INTRODUCCIÓN}

La realización del mercado mundial ha llegado en oleadas. Colonización, imperialismo y globalización han derrumbado «todas las murallas chinas» (Marx y Engels, 2000, p. 32). En la actualidad la expansión del capital ha colisionado con los límites del espacio planetario y está volviendo sobre sí mismo, intensificando sus redes, acelerando sus circuitos y colapsando todas las distinciones morfológicas en un remolino de acumulación atestado de tensiones y crisis. 
Esta creciente tendencia dentro de la geografía histórica del capitalismo global ha comenzado a ser discutida en términos de «urbanización extendida» (Monte-Mor 2014a), «la urbanización del mundo» (Soja and Kanai, 2014) y «urbanización planetaria» (Brenner, 2014a). De acuerdo a esta emergente literatura, la división entre lo rural y lo urbano ha perdido validez conceptual y debe ser reemplazada por una fluida dialéctica de implosión-explosión, que explica mejor la masiva concentración del capital y la agresiva expansión del tejido urbano que caracterizan el devenir del mundo contemporáneo.

Esta reconceptualización de los parámetros de la urbanización dirige nuestra atención hacia espacios que han sido previamente observados como externos al espacio de lo urbano: paisajes devastados por la extracción de recursos y extensiones periféricas de «naturaleza salvaje», que han sido tradicionalmente consideradas rurales, pero que ahora están siendo incorporadas a los procesos globales de desarrollo urbano (Brenner and Schmid, 2014). Como apunta Brenner (2014a), «hoy, estos paisajes están siendo producidos, diseñados o rediseñados de forma exhaustiva a través de inversiones en infraestructuras, privatizaciones y estrategias de planeamiento de gran escala territorial que prevén apoyar un crecimiento acelerado y la expansión de las aglomeraciones a lo largo del mundo» (p. 20). En este artículo, exploramos este proceso en el caso de la Amazonía ecuatoriana. Desde su elección en 2006, el presidente de Ecuador, Rafael Correa, ha implementado un proyecto de modernización guiado por el Estado bajo el nombre de "posneoliberalismo» (SENPLADES, 2011) como parte del conjunto de nuevos gobiernos progresistas que han llegado al poder en los últimos quince años. La estrategia de desarrollo de Correa se ha centrado en la construcción de grandes infraestructuras de transporte y energía que pretenden catalizar la «transformación de la matriz productiva» pasando de la dependencia de recursos primarios a una economía del conocimiento «biosocialista». Una dimensión central de este proyecto es el desarrollo de la Amazonía ecuatoriana, que ha sido históricamente la región de Ecuador más marginada y empobrecida. A través de un conjunto de ambiciosos megaproyectos urbanos, la administración de Correa está tratando de romper la dependencia que la economía nacional tiene en relación con los campos petroleros de la Amazonía, en rápido agotamiento, mientras se integra completamente la región al territorio nacional.

¿Qué puede ilustrar el caso ecuatoriano sobre las posibilidades y limitaciones de un proyecto posneoliberal bajo las condiciones de la urbanización planetaria? Para responder esta pregunta, desarrollamos una teoría propia sobre este concepto. Los pioneros de este concepto nos han provisto de conocimientos y perspectivas invaluables sobre la forma y el contenido de la urbanización planetaria (ver Brenner, 2014b; Schmid, 2014; Merrifield, 2014), pero reconocen que su investigación requerirá «innovaciones teóricas y conceptuales» (Brennner and Schmid 2014, p. 163). Por ello, conceptualizamos la urbanización planetaria en términos de una transición tendencial de la subsunción formal a la subsunción real del espacio al capital, a través de la cual, el capital está incrementando su poder como forma abstracta de dominación (Postone, 1993; Smith, 1984). Éste no es un proceso automático, sino que es facilitado por proyectos políticos específicos, incluyendo el experimento "posneoliberal» actualmente en marcha en Ecuador. Una amplia variedad de casos empíricos han sido abordados por la literatura sobre urbanización planetaria, incluyendo casos localizados en la Amazonía (ver 
Kanai, 2014; Monte-Mor, 2014b). Sin embargo, esta literatura no ha dado una atención adecuada a las inherentes contradicciones político-económicas de este proceso, a través de los cuales se concreta en lugares específicos. Por lo tanto, abordamos la política de la urbanización planetaria en el caso de la Amazonía ecuatoriana, a través de la exploración de las formas en las que un proyecto político que busca confrontar el poder del capital global puede acabar reforzándolo mediante la producción del espacio.

Comenzamos delineando una conceptualización inicial de la urbanización planetaria en términos de la subsunción real del espacio al capital, a través de la cual el capital está incrementando su poder como forma abstracta de dominación. Posteriormente analizamos la relación entre el post-neoliberalismo y la producción del espacio en el caso de la Iniciativa para la Integración de la Infraestructura Regional Suramericana (IIRSA), que Brenner (2014b, p. 184) ha identificado como caso paradigmático de urbanización planetaria. El siguiente apartado identifica las bases ideológicas del posneoliberalismo en Ecuador, en relación a la implementación del IIRSA bajo la administración de Correa. Localizamos este proyecto dentro de la historia de la urbanización de la Amazonía ecuatoriana, argumentando que la complejidad del proceso sugiere que la subsunción real del espacio al capital debiera ser desagregada en tres dimensiones interrelacionadas: territorio, naturaleza y vida cotidiana. Por tanto, esta reconceptualización está centrada en el análisis de tres mayores proyectos urbanos que están siendo implementados en la actualidad en la Amazonía ecuatoriana: el corredor de transporte Manta-Manaos (territorio), la universidad de «bioconocimiento» Ikiam (naturaleza), y una serie de «Ciudades del Milenio» (vida cotidiana). En cada caso, mostramos cómo una estrategia política posneoliberal amenaza con profundizar de forma supuestamente no intencionada la subsunción real del espacio al capital. Sin embargo, las contradicciones sustantivas del capitalismo global implican que estos proyectos solo tendrán éxito intensificando la subsunción formal de la Amazonía ecuatoriana dentro de una amplia dialéctica de la subsunción formal y real a través de la que la urbanización planetaria avanza en la escala global.

\section{CAPITAL COMO EL SUJETO DE LA URBANIZACIÓN PLANETARIA}

La literatura sobre la urbanización planetaria evoca imágenes de paisajes vacíos, distopías urbanas sin fin y destrucción creativa en una escala inimaginable, todo lo cual ha sido descrito por Brenner (2014b) como «lo sublime apocalíptico» (p. 26). Brenner no desarrolla la idea, pero Slavoj Žižek ha descrito lo sublime como «la paradoja de un objeto que, en el campo mismo de la representación, proporciona un punto de vista, de un modo negativo, de la dimensión de lo que es irrepresentable» (Žižek 2003, p. 260). Ello sugiere que la concepción de la urbanización planetaria expresa y oculta algo que fracasa en representar adecuadamente, y que solo puede ser referido a través de las representaciones sublimes. En este artículo, utilizamos el trabajo de Moishe Postone para sostener que este algo es el poder emergente del capital como sujeto (Postone, 1993). ${ }^{2}$ Postone sigue el argumento de Marx respecto a que el valor en la sociedad capitalista está constituido por el tiempo de trabajo socialmente necesario y que la producción capitalista está basada en el único propósito de extraer el plusvalor a través de la explotación del trabajo vivo. La reproducción ampliada del capital obliga progresivamente a 
todos los capitalistas a obedecer esta lógica monolítica de la autovalorización, y el capital ejerce una forma abstracta de dominación que conduce hacia «la acumulación por la acumulación», a pesar de las consecuencias sociales o ecológicas. Postone argumenta que, por ello, el capital, más que el proletariado, constituye el verdadero sujeto de la historia; un sujeto que el propio proletariado crea a través de su actividad de producción alienada. Como el sujeto emergente del capitalismo global, el capital es «ciego, procesual y cuasi-orgánico [...] Un Otro alienado, abstracto y auto-motriz, caracterizado por un movimiento direccional constante sin objetivo externo» (Postone, 1993, pp. 270, 278). ${ }^{3}$

El capital emerge primero como una forma abstracta de dominación con la consolidación de lo que Marx conceptualiza como la subsunción formal del trabajo al capital: la subordinación de formas pre-existentes de producción bajo el dominio del trabajo asalariado. Sin embargo, la subsunción formal está limitada a la producción de plusvalor absoluto. Éste solo se pude incrementar a través de la extensión de la jornada de trabajo que como tal tiene límites concretos. En su deseo ciego por la autovalorización infinita, el capital promueve una transición de la subsunción formal a la subsunción real del trabajo a través de la cual el proceso de trabajo se transforma de acuerdo a los requerimientos del capital. La subsunción real permite la producción de plusvalor relativo a través de la utilización de las tecnologías que incrementan la productividad del trabajo y la tasa de plusvalor (Marx, 1976, pp. 1019-1038). ${ }^{4}$ A través de este proceso, el capital se consolida cada vez más como forma abstracta de dominación. Por ello, la transición de la subsunción formal a la subsunción real del trabajo es la forma que dinamiza el surgimiento del capital como sujeto (Postone 1993, pp. 283-284). ${ }^{5}$

La subsunción real del trabajo conlleva la correspondiente transición de la subsunción formal a la subsunción real del espacio. Si inicialmente el capital ocupa y explota el espacio como lo encuentra, el salto a la subsunción real implica la transformación concreta del espacio en un aparato para la producción y realización de plusvalor relativo, a través de obras como la construcción de redes de transporte que reducen «el tiempo de rotación socialmente necesario» (Harvey 1982, p. 186). Esta relación ha sido apuntada por Neil Smith (1984):

El capitalismo define la escala geográfica global de acuerdo a su propia imagen. Como forma de universalizar la ley del valor, la expansión del capitalismo llena el contenido político y económico [...] del espacio que hereda. Cuando esta expansión absoluta se aproxima a los límites de la escala global, el aspecto formal de la integración espacial a través del mercado es subsumido de forma progresiva bajo una tendencia hacia la integración espacial real. Teóricamente, el paralelismo con la idea de Marx - que hay una transición desde la subsunción formal a la subsunción real del trabajo al capital— es exacta. (p. 186)

Si la globalización tiende a la realización del mercado mundial en términos formales, a través de la liberación del capital a escala global, la urbanización planetaria puede ser comprendida en términos de una correspondiente tendencia hacia su compleción en términos reales, en que la «dominación abstracta no solo determina la finalidad de la producción [...] sino su forma material como tal» (Postone, 1993, p. 30). Este proceso toma múltiples formas concretas, incluyendo la integración de megalópolis globales, la producción de sistemas de transporte y energía trasnacionales, y la apertura de nuevos espacios a la extracción de recursos requeridos 
para sostener la circulación acelerada de capital a través de estas redes globales. Así, el espacio planetario se convierte en una fuerza de producción unificada, una máquina global para la infinita producción de plusvalor relativo. A través de este proceso de urbanización total, el capital incrementa su poder como forma abstracta de dominación, $\mathrm{y}$ «cumple su propia agenda de acumulación por la acumulación, producción por la producción» (Harvey, 2014, p. 58). Es en este sentido que el capital es el sujeto de la urbanización planetaria. El resto del artículo desarrolla esta tesis preliminar a través de la exploración de las relaciones entre posneoliberalismo y urbanización planetaria en la Amazonía ecuatoriana.

\section{POSNEOLIBERALISMO Y LA PRODUCCIÓN DEL ESPACIO}

La urbanización planetaria no es un proceso automático, sino que se hace realidad a través de estrategias estatales específicas, que producen el espacio material requerido para la acumulación global del capital (Brenner, 2013, p. 42). Un proyecto paradigmático a este nivel es la Iniciativa para la Integración Regional de Sudamérica (IIRSA), un programa de desarrollo regional que comprende a los doce estados sudamericanos, y que busca reorientar las infraestructuras de energía, transporte y comunicación de todo el continente hacia los circuitos trasnacionales de capital. La IIRSA reestructura el espacio de Sudamérica en diez «Ejes de Integración y Desarrollo» que trascienden las fronteras nacionales y abren corredores interoceánicos para el flujo libre de mercancías mediante la construcción y modernización de puertos, aeropuertos, puentes, túneles, carreteras, ferrocarriles, centrales hidroeléctricas y redes eléctricas (COSPILAN, 2013, p. 33). ${ }^{6}$ Así, la IIRSA aparece como una estrategia para la subsunción real del espacio al capital, mediante la aceleración de los circuitos globales y la reducción del tiempo de rotación socialmente necesario a escala planetaria.

La IIRSA fue lanzada en 2000, y en 2009 fue incorporada al nuevo Consejo Suramericano de Infraestructura y Planeamiento (COSIPLAN), como parte de la Unión de Naciones Suramericanas (UNASUR). Creada en 2008, la UNASUR es la primera organización regional que incluye a las doce naciones sudamericanas. Se presenta como un modelo de «regionalismo posneoliberal», que no está limitado a la facilitación del intercambio económico, sino que «tiene como objetivo construir [...] un espacio de integración y unión en lo cultural, social, económico y político» (COSIPLAN 2013, p. 17). Las raíces de UNASUR son una serie de tratados de libre comercio desde inicios de la década de los años 90 del siglo XX, y la IIRSA fue planificada originalmente por el Banco Interamericano de Desarrollo (BID), como parte de una estrategia para proveer el apuntalamiento de las infraestructuras para el Área de Libre Comercio de las Américas (ALCA) promovido por los EE.UU. (Banco Interamericano de Desarrollo 2001, 2010). ${ }^{\text {? }}$

La explicación de esta aparente paradoja radica en el neoestructuralismo, el fundamento ideológico dominante del posneoliberalismo en Sudamérica, que ha sido promovido desde los años 90 por la Comisión Económica para América Latina y el Caribe (CEPAL) (Leiva, 2008a; 2008b). En los años 40 y 50 del siglo XX, la CEPAL fue el centro intelectual del estructuralismo, que buscaba liberar América Latina de la estructura centro-periferia del capitalismo global mediante la Industrialización por Sustitución de Importaciones (ISI). El fracaso de la 
ISI, el triunfo del neoliberalismo y las brutales consecuencias sociales de esta transición hicieron que la CEPAL tuviera una profunda crisis intelectual. De modo que la CEPAL abandonó el modelo centro-periferia y su crítica a las estructuras globales de acumulación de capital, y abrazó la agenda «neoestructuralista» de la «competitividad sistémica», de acuerdo con la que un amplio rango de las políticas económicas y sociales prepararían a sociedades enteras para la «competencia exitosa en los mercados mundiales» (Leiva, 2008b, p. 3), reemplazando la competitividad «espuria» basada en salarios baratos y recursos naturales con una competitividad «autentica» basada en el incremento de la productividad y la innovación tecnológica (Leiva, 2008a, p. 113).

Este impulso hacia la competitividad internacional, y su abstracción de las relaciones de poder del capitalismo global, han llevado a Fernando Leiva a concluir que «el neoestructuralismo de América Latina no es una alternativa al neoliberalismo, sino que completa la tarea histórica iniciada por éste: la consolidación y legitimación de un nuevo régimen de acumulación orientado a las exportaciones» (Leiva, 2008b, p. 15). Esta convergencia ideológica hacia «la política de la competitividad global» (Cammack, 2006) explica la continuidad entre las versiones «neoliberal»y «posneoliberal» de la IIRSA, que tiene sus bases en el supuesto de que «la infraestructura física sirve como plataforma para el crecimiento y la competitividad» permitiendo a la región «aprovechar las ventajas ofrecidas por la globalización» (COSIPLAN, 2013, pp. 21, 17). Pero hay una contradicción aún más profunda aquí. En principio, el posneoliberalismo persigue ir más allá de las contradicciones del capitalismo mediante la consecución de la competitividad sistémica. Pero es precisamente esta dinámica de la competitividad capitalista la que conduce a la transición a la subsunción real mediante la cual el capital incrementa su poder como forma abstracta de dominación. En palabras de Marx, «la competencia es la forma adecuada del proceso productivo del capital. Cuanto más es desarrollada, más puras son las formas en las que aparece su propuesta [...] [El capital] lanza sus mulares y se mueve de acuerdo a sus propias leyes» (Marx, 1973, p. 651). Por ello, la ironía del posneoliberalismo es que su búsqueda de la competitividad sistémica está destinada a consolidar las fuerzas del capital de las que, supuestamente, se esfuerza por escapar.

Esta contradicción está bien ilustrada en el caso de Ecuador, que es observado como uno de los experimentos más radicales de América Latina del posneoliberalismo (Ellner, 2012; Burbach, Fox and Fuentes, 2013). Las reformas neoliberales dieron comienzo en Ecuador en los años 80 del siglo XX, implicando privatizaciones, desregulaciones, la apertura de la explotación petrolera a nuevos capitales extranjeros, y la prioridad del pago de la deuda externa respecto a los gastos sociales. Los costes de estas políticas fueron asumidos por los sectores populares del Ecuador, y especialmente por la históricamente excluida población indígena, cuyas organizaciones lideraron una serie de levantamientos populares que contribuyeron a la profundización de la crisis del capitalismo ecuatoriano (Arsel, 2012; Becker, 2011; Kennemore and Weeks, 2011).

En 2006 Rafael Correa fue elegido sobre la base de una plataforma que prometió sacar al país de la «larga noche neoliberal» (Radcliffe, 2012; Walsh, 2010). Desde su llegada al poder, Correa implementó de inmediato una serie de medidas para abordar los peores excesos del periodo neoliberal, rechazando un tratado de libre comercio con Estados Unidos, cerrando 
una base militar estadounidense, expulsando del país al representante del Banco Mundial y cobrando a las oligarquías locales por los bienes incautados por la banca deudora al Estado. Ecuador se negó a cumplir los pagos de la deuda externa y renegoció los contratos petroleros, mientras que se extendió la participación de las empresas estatales en la producción de petróleo. El resultado fue una alza de los ingresos públicos, favorecido además por los altos precios del petróleo, lo que ha permitido una expansión del gasto público, incrementándose desde los dos mil millones de dólares en 2006 a los once mil millones en 2012 (SENPLADES, 2014, p. 104). Lo cual ha sido en parte dirigido hacia gasto en salud, educación, y programas de bienestar, generando un significativo descenso en los índices de pobreza y desigualdad (Escribano, 2013).

Pese a estos éxitos, la administración de Correa ha sido acusada de fracasar en el cambio de las históricas estructuras de acumulación de capital y dominación de clase en Ecuador (Acosta, 2013; Unda, 2013). De hecho, el crecimiento económico y la estabilidad política catalizada por las inversiones del Estado en obras públicas y programas sociales ha sido bien recibida por la clase capitalista nacional, y de acuerdo con ciertas variables la concentración de la riqueza y el poder en el país se han incrementado (Ruiz, 2013, pp. 111-125). Recientemente, el gobierno está promoviendo asociaciones público-privadas, un tratado de libre comercio con la Unión Europea y ha reestablecido las relaciones con el Banco Mundial y el Fondo Monetario Internacional, llevando a la revista empresarial The Economist (2014) a comentar que «el Sr. Correa se está volviendo más pragmático». Como Marc Becker (2013b, p. 113) ha concluido: «de las numerosas izquierdas que han llegado al poder en América Latina, Correa representa una posición moderada y ambigua más cercana a Lula en Brasil o a la Concertación en Chile, que al socialismo del siglo XXI de Chávez o al socialismo comunitario de Morales».

Esta cercanía del gobierno ecuatoriano con los gobiernos progresistas de América Latina más «pragmáticos» se basa en su adhesión ideológica al neoestructuralismo y la competitividad sistémica. ${ }^{8}$ El manifiesto de 2006 del nuevo partido de Correa, Alianza País, anunció que «soñamos con un país competitivo, en el marco de una competitividad sistémica» y prometió crear «un sistema productivo competitivo y abierto a la competencia con el exterior» (Alianza País, 2006, pp. 8, 17). Una vez en el poder, el gobierno ha buscado de forma consistente «la inserción estratégica en la economía mundial», promoviendo «la inversión privada» y profundizando «la inversión pública como generadora de condiciones para la competitividad sistémica» (SENPLADES 2014, p. 78-79). ${ }^{9}$ Esta estrategia se ha centrado en la construcción de infraestructura económica de gran escala. El último plan de desarrollo cita un documento de CEPAL sobre el rol de la infraestructura, la cual «incrementa la competitividad y reduce los costos de producción, expandiendo con ello la actividad comercial, la inversión privada y la acumulación de capital» (SENPLADES, 2014, p. 1065). Coherente con esta estrategia, en la administración de Correa, la mayor inversión pública se ha realizado en construcción de autovías, puertos, aeropuertos y proyectos hidroeléctricos. (Dávalos y Albuja, 2014, pp. 157-158; Escribano, 2013, pp. 157-158). Muchos de estos proyectos están incluidos o son complementarios a la IIRSA. En 2013 un total de 46 proyectos de la IIRSA fueron localizados de forma completa o parcial en el territorio ecuatoriano, incluyendo la construcción o modernización de 10 autopistas, 7 puertos, 5 aeropuertos, 3 puentes, 2 represas, 4 redes eléctricas, 3 redes de comunicación, 3 hidrovías (ríos modernizados) y 9 pasos fronterizos (COSIPLAN, 2013). ${ }^{10}$ 
Muchos de estos proyectos se ubican en la Amazonía ecuatoriana. La Amazonía ha sido históricamente la región más marginada del país y uno de los principales objetivos de desarrollo del gobierno de Correa, es integrarla completamente al territorio nacional a través de la construcción de infraestructuras económicas y grandes proyectos urbanos. Sin embargo, dentro de las coordenadas espaciales de la IIRSA y de la política económica de la competitividad sistémica, este proyecto de integración nacional implica simultáneamente la incorporación de la región en las dinámicas de urbanización planetaria y el fortalecimiento del capital como una forma abstracta de dominación. En lo que resta, el artículo explora las dimensiones territorial, natural, y cotidiana de este proceso, después de localizarlo en su contexto histórico-geográfico.

\section{LA URBANIZACIÓN DE LA AMAZONÍA ECUATORIANA}

La urbanización de la Amazonía ecuatoriana puede ser dividida esquemáticamente en cuatro fases (ver Figura 1). Ecuador entró al mercado mundial con la invasión española en 1531 y la primera fase de la urbanización amazónica comenzó siete años después, con la búsqueda de oro. Durante el siglo XVI la colonización del norte de la Amazonía se consolidó, mientras que en el sur, la población Shuar llevó adelante una serie de levantamientos que expulsó a los españoles de sus colonias, estableciendo un patrón de desarrollo geográfico desigual que ha persistido desde entonces. La ocupación colonial se consolidó alrededor de la ciudad de Baeza con colonias a lo largo del territorio de los Quijos, quienes desaparecieron a causa de las masacres, las enfermedades y los trabajos forzados en las encomiendas. Como su número descendía, la colonia española trajo kichwas de la sierra para reemplazarlos con el fin de mantener el trabajo forzado agrícola requerido para sostener el consumo de la capital, Quito. En el interior de la Amazonía, las misiones católicas construyeron una serie de «reducciones» que eran nuevas aldeas en las que la población indígena dispersa era forzada a concentrarse y trabajar, en ciertos casos, en la recolección de oro. (CDES, 2011; Deler, 1983; García, 1985; Gutiérrez, 2002; Cipolletti, 1988; Vickers, 1989).

La decadencia de la colonia en los comienzos del siglo XIX terminó con esta fase inicial de protourbanización. A lo largo de las décadas siguientes el sistema hacendatario dominó el norte de la región. Este sistema se basó en mano de obra esclava capturada a lo largo de «correrías» mediante una serie de ataques lanzados desde Colombia y Perú, que provocaron el vaciamiento del espacio y crearon la fuerza de trabajo requerida por el boom del caucho el final del siglo XIX. El boom lanzó una segunda fase de urbanización incipiente y reorientó el flujo de recursos hacia el Atlántico. El caucho era llevado por el río Napo hasta el centro urbano en expansión de Iquitos, en Perú, y a lo largo del Amazonas hasta Manaos, ciudad en auge en Brasil, desde donde era transportado a la costa Atlántica y exportado a los centros industriales de Europa. En el comienzo del siglo XX el boom languideció y la actividad económica regional se desplazó a la producción agrícola para el crecimiento del mercado interno de la sierra que catalizó una nueva oleada de colonización. En 1941 la disputa territorial con Perú llevó a una guerra en la que Perú se anexó la mitad del territorio nacional ecuatoriano, todo lo anexado por Perú que en su totalidad correspondía a la región amazónica. Ecuador reforzó sus nuevas fronteras con puestos militares y abrió las regiones fronterizas a migrantes kichwa, 
Figura 1. La urbanización del norte de la Amazonía ecuatoriana

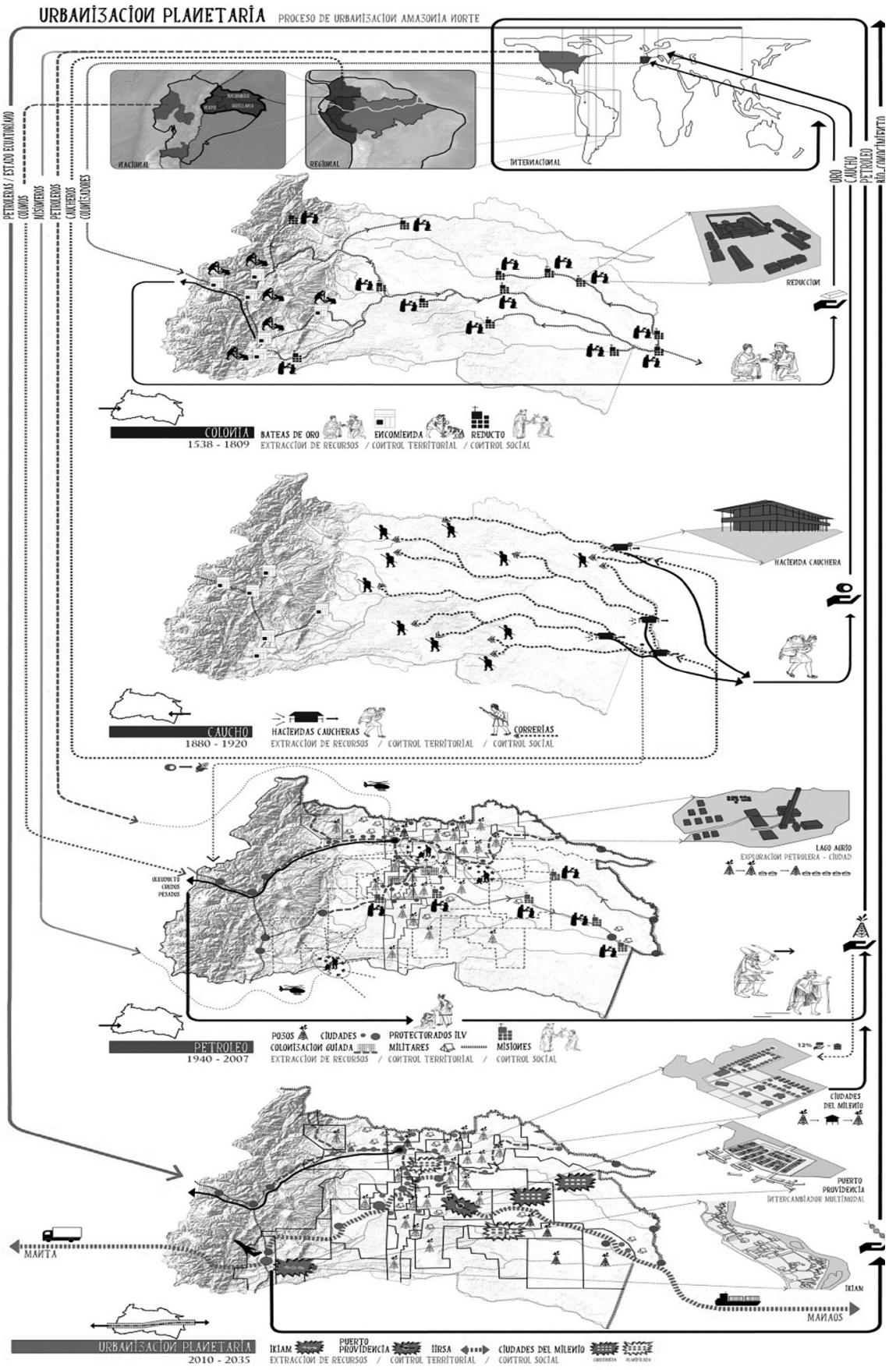

Fuente: Autores. 
significando el comienzo de la tercera fase, esta vez más intensa, de urbanización (CDES, 2011; Galarza, 1972; Muratorio, 1987).

En los años 50 nuevas misiones católicas se establecieron a lo largo de las riberas de los ríos del norte del Napo y del Aguarico, creando asentamientos en los que la población kichwa fue relocalizada. ${ }^{11}$ Mientras tanto, una organización evangelista estadounidense, el Instituto Lingüístico de Verano, comenzó a crear nuevos reasentamientos que repitieron la estrategia colonial de las reducciones para la concentración de la población indígena. ${ }^{12}$ Como en el periodo colonial, la estrategia funcionó para vaciar grandes extensiones de territorio y facilitar la creación de enclaves para la extracción de recursos. La exploración petrolera había dado comienzo en la región desde la década de los 40, y fue la razón subyacente de la guerra entre Perú y Ecuador. Finalmente, la explotación comenzó en 1967 a cargo de la empresa estadounidense Texaco-Gulf. La industria petrolera requirió la construcción de una malla de carreteras y oleoductos que unieron la Amazonía a la Sierra y la Costa, desencadenando la explosión del desarrollo urbano en la región. Repentinamente nuevas ciudades emergieron alrededor de las mayores centrales de procesamiento del petróleo, como fue el caso de Lago Agrio, Coca, Shushufindi y Joya de los Sachas. Algunos poblados comenzaron a desarrollarse en los nodos de comunicación y en las centrales de procesamiento más pequeñas, y las nuevas carreteras, abiertas a lo largo de extensos tramos de selva, fueron rápidamente colonizadas por migrantes de la Sierra y la Costa (Bayón, 2013; Carrión y Cuvi, 1985; Maldonado, 2001). ${ }^{13}$ Esta dinámica de la época desarrollista continuó durante el periodo neoliberal, en el que se incrementó la participación de las compañías extranjeras en la explotación petrolera, acompañado de un rápido crecimiento urbano que aceleró la colonización a lo largo de las carreteras construidas para extender la frontera petrolera, que dio lugar a un proceso de «protourbanización» caótico y fuertemente destructivo (Barbieri, Monte-Mor and Bilsborrow, 2007). Para la población indígena, esta última ola de urbanización implicó desposesión, empobrecimiento, enfermedades fruto de la contaminación petrolera y en los casos de Teetetes y Sansahuaris, la desaparición de pueblos completos (Aguirre, 2010, p. 50).

Hasta este momento, la Amazonía ecuatoriana había sido urbanizada a través de un complejo proceso histórico de expansión y consolidación territorial, extracción y exportación de materias primas, y desposesión y civilización de la población indígena. Pero estas dimensiones entrelazadas de territorio, naturaleza y vida cotidiana solo habían sido formalmente subsumidas. La naturaleza había sido directamente explotada en las condiciones en las que fue encontrada. El territorio nacional era un embrollo de procesos caóticos contenidos en una frágil frontera y la población indígena no había sido transformada en una dócil y productiva fuerza de trabajo. Por estos motivos, la Amazonía ecuatoriana constituyó una de las regiones del planeta que Smith (1984) describe como áreas que son «integradas en el sistema mundo capitalista como externalidades internalizadas. Por definición, no han sido atravesadas por una transición completa de la integración formal a la integración real y la integración real del espacio global económico, queda necesariamente incompleta» (pp. 188-189).

Cuando Correa llegó al poder en 2007, la Amazonía era una de las regiones del territorio nacional más marginadas y empobrecidas. En cambio, hoy en día, uno de los principios de la estrategia nacional de desarrollo del gobierno es la promoción de la equidad territorial a 
través de la implementación de proyectos estratégicos en las regiones «menos desarrolladas», incluida la Amazonía (SENPLADES, 2011, pp. 39-40). ${ }^{14}$ Muchos de los proyectos de desarrollo para la región están incluidos o relacionados a la IIRSA; como el corredor multimodal de transporte Manta-Manaos, el cual busca abrir una conexión interoceánica entre las costas del Pacífico y del Atlántico, vía Manaos en la Amazonía brasileña; Ikiam, una universidad pública que está siendo construida actualmente en la ruta Manta-Manaos y que está designada para explotar los recursos genéticos de la región; y las Ciudades del Milenio, una serie de nuevos poblados planeados a lo largo de la Amazonía, de los cuales uno está localizada en el corredor Manta-Manaos. ${ }^{15}$

Estos proyectos son parte constitutiva y simbólica de la urbanización planetaria de la Amazonía ecuatoriana, entendida como una cuarta fase de urbanización basada en una evolución cualitativa de la subsunción formal a la subsunción real del espacio al capital en las tres dimensiones entrelazadas que han emergido de este breve bosquejo histórico: territorio (MantaManaos), naturaleza (Ikiam) y vida cotidiana (Ciudades del Milenio). El siguiente apartado de este artículo ofrece algunas observaciones preliminares sobre cada uno de los casos, como prólogo de la futura investigación empírica.

\section{TERRITORIO: EL CORREDOR DE TRANSPORTE MULTIMODAL MANTA-MANAOS}

El proyecto Manta-Manaos es promovido por el gobierno ecuatoriano como un «proyecto prioritario del Gobierno del Presidente Rafael Correa, que a través de carreteras y transporte fluvial unirá el puerto manabita [...] con el corazón de la Amazonía brasileña y con el Océano Atlántico» (Ministerio de Relaciones Exteriores, 2013). La parte ecuatoriana del corredor incluye la modernización del puerto de Manta, la construcción o modernización de 810 km de vías, la construcción del aeropuerto de Manta, el puerto de Providencia en el río Napo y la modernización del río Napo aguas arriba de la frontera con Perú. El corredor está diseñado para competir con las rutas del canal de Panamá y de Los Ángeles-Miami, a través de las cuales se está llevando a cabo, actualmente, el comercio entre Brasil y el este de Asia, mientras que se abre el interior de la Amazonía peruana y ecuatoriana a los mercados de Europa y al este de los EE.UU. (Ministerio de Relaciones Exteriores, 2010). El proyecto está incluido en el IIRSA como un conjunto de proyectos para el Eje de Integración y Desarrollo Amazónico. El Eje Amazonas incluye ochenta y ocho proyectos con un coste total proyectado de 29 mil millones de dólares. Estos proyectos están organizados en ocho grupos, los cuales están centrados en la apertura de la Amazonía al capital trasnacional mediante una serie de rutas interoceánicas de transporte entre los océanos Pacífico y Atlántico (COSIPLAN 2013, pp. 69-94).

Tres de estas rutas atraviesan Ecuador por tres de los ríos tributarios del Amazonas: el Putumayo en la frontera norte con Colombia, el Morona-Marañón en el sur y el Napo, en el corredor Manta-Manaos, el cual es el más avanzado de los tres. ${ }^{16}$ Junto con otros proyectos complementarios de escala nacional, estos proyectos buscan crear «una franja multinacional del territorio [...] articulada por la infraestructura de transporte, energía y comunicaciones que facilita el flujo de bienes y servicios» (COSIPLAN, 2013, p. 19). 
La incorporación de Ecuador a la IIRSA puede ser conceptualizada en términos de una evolución de la subsunción formal a la subsunción real del territorio al capital global. Mientras los acuerdos regionales previos han sido pensados simplemente para unificar el espacio comercial entre distintos estados, los promotores de la IIRSA argumentan que «la integración física crea un vínculo más permanente entre las naciones [...] No se trata de consolidar las fronteras nacionales, como antes, sino ampliarlas en el sentido de su dilución» (Soares de Lima, 2008, pp. 24, 26). En este contexto, «el control estatal sobre el territorio [...] es menos importante que la capacidad para conservar un orden espacial necesario para el crecimiento económico» (Bryan, 2012, p. 218). En el caso del corredor Manta-Manaos, este cambio es una expresión de la tendencia inmanente del capital hacia la «aniquilación del espacio por el tiempo» (Marx, citado en Harvey 2001, p. 244). Los planes del proyecto Manta-Manaos están basados en el concepto «menor tiempo, menor costo», en comparación con las rutas comerciales globales alternativas (Ministerio de Relaciones Exteriores, 2010), y predicen que el proyecto transformará Ecuador en «el mejor punto de intercambio [...] comercial entre los países de la Cuenca del Pacífico y la Cuenca Amazónica» (Autoridad Portuaria de Manta, 2006). El objetivo es capitalizar esta posición dentro de los circuitos trasnacionales de capital, mediante la creación de redes de áreas de libre comercio, incluyendo los puertos de Manta y Providencia. Estas áreas son «integradas a corredores funcionales», incluyendo Manta-Manaos, que permitirán «mejorar la competitividad del sector productivo nacional [...] [y] concentrar flujos de mercancías en determinados nodos logísticos para generar economías de escala [...] orientados al comercio exterior» (Ministerio de la Producción, Empleo y Competitividad, 2013). ${ }^{17}$

Sin embargo, como ha explicado David Harvey, la incorporación completa del espacio nacional a los circuitos globales de capital, lo somete a una competencia intercapitalista a nivel del mercado mundial, con el resultado de que su competitividad puede ser erosionada en lugar de mejorada (Harvey 1982, p. 427). Además, está claro, por la naturaleza de los intereses de los inversores en el corredor Manta-Manaos, que el capital global ve a Ecuador como un mero obstáculo a reducir para allanar el terreno y acelerar el flujo de mercancías. Para el capital de Asia del Este, el proyecto tiene el simple interés de reducir el tiempo y los costes de transporte de los componentes electrónicos hasta el emergente centro industrial de Manaos, donde sus empresas ensamblan equipos electrónicos para el mercado sudamericano. ${ }^{18}$ El capital brasileño, igualmente, mira al corredor como una vía más rápida y más barata para los 9 mil millones de dólares en materias primas que anualmente exporta a Asia del Este. ${ }^{19}$ En esta dinámica planetaria, el único rol «competitivo» de Ecuador se sustenta en la provisión de materiales de construcción y productos alimenticios básicos para mantener la fuerza de trabajo industrial de Manaos, como reconoce el gobierno ecuatoriano en su promoción del proyecto (Ministerio de Relaciones Exteriores, 2010). Irónicamente para un proyecto «neoestructuralista», Manta-Manaos estaría entonces contribuyendo a la consolidación de una nueva configuración de la estructura centro-periferia, que el neo-estructuralismo ha abandonado teóricamente, en la cual el corazón industrial se ha trasladado desde Europa hacia Asia; Brasil está reincorporado sobre la base de una fuerza de trabajo industrial barata; y Ecuador permanece atrapado en su rol tradicional como primario-exportador. 
A pesar de ello, es poco probable que estos resultados accidentales lleguen a darse. Los elementos centrales del proyecto están siendo implementados; incluyendo el arranque de la construcción del puerto de Providencia y la finalización de la vía de conexión con Shushufindi en la ruta hacia Manta, ambos desarrollados en 2014 (Ministerio de Transporte y Obras Públicas, 2014). Pero entrevistas con funcionarios del gobierno sugieren que el desarrollo del puerto de Manta está bloqueado por poderosos intereses de clase asociados al negocio de la importaciónexportación del principal puerto de Ecuador, Guayaquil. El río Napo también constituye un gran obstáculo: se presenta innavegable para grandes barcos de contenedores, y cambia continuamente su curso y profundidad, lo que requiere un gran proyecto de ingeniería con fuertes consecuencias ambientales, y cuenta con la oposición de los movimientos indígenas y ecologistas de la región (El Telégrafo, 2011) ${ }^{20}$ Sin una ruta de salida funcional al Océano Pacífico o al interior de la Amazonía, el proyecto permanecerá confinado en los límites de sus fronteras nacionales. En este contexto, el desarrollo de la vía e infraestructura portuaria alrededor de Providencia no llevará al Ecuador a una «inserción inteligente en los mercados internacionales», si no que abrirá nuevas extensiones de la Amazonía ecuatoriana a la colonización agraria y la extracción de materias primas. En otras palabras, Manta-Manaos solo conseguirá consolidar la subsunción formal del territorio al capital.

\section{NATURALEZA: IKIAM, UNIVERSIDAD DE LA AMAZONÍA}

La estrategia económica del gobierno de Correa está basada en la «transformación de la matriz productiva». La acumulación de capital y los presupuestos del Estado siguen dependiendo en gran medida de la explotación de las reservas petroleras de la Amazonía, perpetuando la destrucción ambiental y el conflicto social, mientras la economía queda expuesta a la volatilidad de los mercados internacionales. Se espera que las reservas de petróleo se acabarán en un plazo de entre 15 y 25 años (Iturralde, 2013), y por ello es urgente la necesidad de transformación. En la planificación de esta transición, la administración de Correa ha diseñado un «cambio estructural» bajo la inspiración de la estrategia de la CEPAL (CEPAL, 2012, p. 17; SENPLADES, 2014, p. 79), que «requiere un cambio hacia la exportación con alto valor agregado y una competitividad internacional basada en el incremento de la productividad [...] garantizando una inserción más dinámica en los mercados mundiales» (Leiva 2008b, p. 6). El manifiesto original de Alianza País propone que «un incremento de la competitividad sistémica debe basarse en el mejoramiento de la productividad de amplios segmentos del aparato productivo» (Alianza País, 2006, p. 16). Esta estrategia es el fundamento de los planes de desarrollo que han buscado diseñar la transición desde la economía primario-exportadora a la «economía del bioconocimiento», basada en la biodiversidad inmensa de la Amazonía. ${ }^{21}$

Ikiam, que significa «Naturaleza» en lengua shuar, es central en esta estrategia. Ikiam es una universidad pública construida en la Amazonía ecuatoriana, localizada a $8 \mathrm{~km}$ de la ciudad del Tena, al pie de los Andes. El nuevo aeropuerto de Tena, de reciente construcción, es parte de la IIRSA y se encuentra en un nodo formado por el Eje Andino y el Eje Amazonas, materializado por el cruce del Corredor Manta-Manaos con la vía andina (COSIPLAN 2013, p. 26). Ikiam está en los límites del Bosque Protector Colonso, una reserva de la biosfera de 93000 hectáreas que 
Correa ha descrito como «el laboratorio más grande del planeta» (El Comercio, 2014c). La universidad se centrará en la «biotecnología» y el «biocomercio» y está enfocada en «generar nueva industria y originar el cambio de matriz productiva» (El Telégrafo, 2014d; 2013d).

Esta transición hacia un desarrollo más «sostenible» de la Amazonía se refleja en la propia arquitectura de la universidad. Los tres ganadores de la primera ronda del concurso de arquitectura para diseñar Ikiam, enfatizan la armonía con los ecosistemas y las culturas indígenas de la región, mediante laboratorios construidos en forma de hojas, viviendas inspiradas en la arquitectura indígena y «puentes que cambian de dirección, de manera orgánica, evocando la estructura arbórea» (El Comercio, 2014a; 2014b). Por consiguiente, Ikiam constituye lo que David Harvey llamaría una «utopía de la forma espacial» (Harvey, 2000, pp. 104-113). Estas utopías fracasan, de acuerdo a Harvey, en la medida en que priorizan la forma sobre el contenido, inscribiendo una ideología utópica en sus estructuras espaciales sin enfrentar críticamente las relaciones sociales que son reproducidas en su interior. Ikiam es planificada como un centro global de biotecnología para exportar secuencias genéticas y otras formas de conocimiento, y para catalizar un gran cambio de la economía nacional desde los «recursos finitos» a los «recursos infinitos» (SENPLADES, 2014, p. 60). Pero bajo las condiciones de la competitividad global es improbable que el resultado sea la emergencia del «biosocialismo republicano» (Ramírez, 2012). En lugar de ello, puede ser que se solo señale una transición desde la subsunción formal a la subsunción real de la naturaleza al capital (Smith, 2007). La explotación del petróleo, de la minería o la deforestación pueden ser concebidas como parte constitutiva de la subsunción formal de la naturaleza, en el sentido de que se apoderan de los recursos naturales como los encuentran y los incorporan directamente a la producción. La biotecnología expresa un cambio cualitativo en esta relación en la que el capital interviene la estructura interna, y generativa de la misma naturaleza, transformándola en una fuerza de producción con la capacidad de intensificar la extracción de plusvalor relativo. Como Boyd, Prudham y Schurman (2008) argumentan, «la forma primaria de subsunción real de la naturaleza es el programa de manipulación genética [...] a través de la aplicación de nuevas biotecnologías [...] el resultado deseado, por supuesto, es elevar las ganancias y disminuir los tiempos de rotación [...] La naturaleza es (re)construida para trabajar más duro, más rápido y mejor» (pp. 18-19).

Si Ikiam tiene éxito y compite en la economía global del conocimiento, quizás contribuya inconscientemente a la transición planetaria desde la subsunción formal a la subsunción real a través de la que el capital se consolida progresivamente como forma abstracta de dominación. ${ }^{22}$ Pero la biotecnología es una industria sumamente competitiva, con universidades y centros privados de investigación compitiendo por subvenciones a escala internacional. En este contexto, Ikiam sería sólo efectiva compitiendo como reserva de recursos genéticos más que como un centro de investigación y desarrollo, en cuyo caso funcionaría principalmente como forma de extracción de recursos primarios, reproduciendo la estructura económica que ha caracterizado la industria petrolera y otros negocios extractivistas a lo largo de la historia de la región (Chávez, 2014; Villavicencio, 2013). ${ }^{23}$ Por ello, como en el caso del corredor Manta-Manaos, Ikiam es una solución espacial especulativa, que trata de catalizar una transformación no intencional desde la subsunción formal a la subsunción real, pero que puede terminar solo reproduciendo las estructuras establecidas de la subsunción formal en forma extendida, dentro de los patrones cambiantes de desarrollo geográfico desigual a nivel planetario. 
En la práctica, la mayor función de Ikiam puede ser ideológica, constituyendo una milagrosa encarnación de la transformación de la matriz productiva que distrae la atención de los límites y tensiones en la consecución de esta transformación emprendida por el régimen de Correa. La concreción Ikiam se anunció en 2013, inmediatamente después de la cancelación de la Iniciativa Yasuní-ITT, mediante la cual el gobierno ecuatoriano hubiera conseguido no explotar el petróleo del interior de la reserva de la biósfera del Yasuní, a cambio de una contribución económica de los contaminadores internacionales. La decisión de explotar las reservas del Yasuní en 2013 fue una expresión de las dificultades de la transformación de la matriz productiva. Actualmente, la totalidad de la Amazonía ecuatoriana ha sido abierta al capital extranjero para la explotación del petróleo, así como ya fue abierto el sector minero a la inversión trasnacional en 2011. En ambos casos, las leyes coercitivas de la competitividad global están forzando al gobierno a considerar la liberalización de sus acuerdos contractuales y las mejoras de los incentivos con la finalidad de atraer inversores extranjeros, obligando a Ecuador a entrar en los mismos procesos de la «competitividad espuria» de los que la agenda de la competitividad sistémica lo estaba supuestamente rescatando (Escribano, 2013; Iturralde, 2013). En este contexto, es significativo que Ikiam, lugar de la biotecnología, está siendo complementado con otros dos campus menos publicitados. Uno en Sucumbíos, en el centro de la industria petrolera del norte de la Amazonía, que se centrará en la ingeniería petroquímica, mientras que el otro, en Zamora en la zona sur minera, se especializará en minería y metalurgia (El Telégrafo, 2013e; 2014b). Eso implica que, más allá de su rol en la generación de una fantasía nacional de la competitividad sistémica basada en el «bioconocimiento», la verdadera función económica de Ikiam puede consistir en su contribución a la expansión de la frontera extractiva. Como otras utopías de forma espacial, Ikiam amenaza entonces con combinar la materialización de una ideología utópica con la reproducción de las relaciones sociales que se está tratando de superar.

\section{VIDA COTIDIANA: EL PROYECTO DE CIUDADES DEL MILENIO}

La integración social y la estabilidad política son centrales en las políticas de competitividad sistémica (Leiva, 2008a, p. 13). Mientras el enfrentamiento de sociedades enteras con la lógica brutal del neoliberalismo generaba múltiples resistencias, el neoestructuralismo «llama a la construcción del consenso sobre la potencia de un nuevo mercado trasnacional orientado a la exportación que se puede apoyar en nuevos acuerdos sociales y políticos» (Leiva, 2008a, p. 52). La administración de Correa ha sido muy exitosa a este respecto, reemplazando el caos del neoliberalismo ecuatoriano con un orden social estable que, en términos generales, apoya el programa económico del gobierno. Sin embargo, como hemos visto, las dificultades para transformar rápidamente la matriz productiva, han generado una creciente dependencia de la extracción de materias primas y ha forzado al gobierno a abrir nuevas reservas al capital extranjero. Aquí, el problema de «cohesión social» reaparece. La competitividad del país en los sectores extractivos esta disminuida por los conflictos, históricamente relacionados con los proyectos mineros y petroleros, particularmente en la Amazonía, donde están localizados todos los nuevos campos petroleros y muchas de las concesiones mineras. Esta historia de 
conflictivos ha sido uno de los principales factores que han detenido las inversiones extranjeras en los campos petroleros y en las concesiones mineras abiertas bajo la administración de Correa (Iturralde, 2014, pp. 147-174).

En 2011 Correa anunció el lanzamiento de las Ciudades del Milenio; una serie de nuevos poblados que serían realizados con las regalías del petróleo y construidos alrededor de los centros de extracción de recursos de la Amazonía. ${ }^{24}$ Las dos primeras Ciudades del Milenio son Playas de Cuyabeno y Pañacocha, inauguradas en 2013 y 2014 respectivamente. Ambas son habitadas por comunidades indígenas afectadas por la apertura del campo de petróleo de Pañacocha, situado en el norte de la Amazonía. ${ }^{25}$ Más que ciudades, son poblados de unos pocos cientos de habitantes y parecen aldeas típicas de los EE.UU., con trazados reticulares de viviendas individuales situadas alrededor de una escuela, un centro de salud, unos campos deportivos, una unidad de policía. De esta forma se rememora Fordlandia, el poblado construido por Henry Ford en la Amazonía brasileña, con el que trataba de reproducir los company towns que había construido en torno a sus fábricas en los EE.UU. (Grandin, 2009). Estos poblados permitieron a Ford regular la vida cotidiana de su fuerza de trabajo, como forma de incrementar su productividad, constituyendo un momento clave en la colonización de la vida cotidiana, mediante la cual la expansión del sistema capitalista mundial ha sido reemplazada de forma creciente por una intensificación de las intervenciones sociales (Lefebvre 2008, pp. 26-28). Esta transición puede ser conceptualizada como un cambio de la subsunción formal a la subsunción real de la vida cotidiana al capital (Smith 2007), en el que la persona trabajadora no es solamente explotada en su estado original, sino que es producida como capital humano en la búsqueda continua por el incremento de la productividad. Como Gramsci observó en su análisis de "Americanismo y Fordismo", el capital requiere de una «fuerza laboral estable y cualificada [...] porque el conjunto humano [...] es una máquina más de la empresa» (Gramsci, 1973, p. 303).

$\mathrm{Al}$ igual que los poblados de Ford, las Ciudades del Milenio transforman la vida cotidiana de sus habitantes. En contraste con la forma de vida anterior de estas comunidades, cada casa de la Ciudad del Milenio está equipada con electricidad, agua, sanitarios, teléfono, computadora con internet, cocina con fogón eléctrico y refrigeradora, y un juego de sofá con dos sillones (El Telégrafo, 2013b; El Universo, 2013b; 2014). En palabras de uno de los habitantes de Playas de Cuyabeno «Me siento como que estoy en los grandes hoteles, éste es mi sueño americano» (El Universo, 2013b). ${ }^{26}$ Este sueño contiene una dimensión disciplinaria: las viviendas están distribuidas a parejas casadas; el acceso a la selva y al río está obstruido por verjas y paseos; y los habitantes tienen prohibido tener animales, cultivar, fermentar chicha, o modificar las estructuras de sus casas (Coba, Cielo and Vallejo, 2014; El Telégrafo, 2013b; El Universo, 2013b). Estas medidas, combinadas con la nueva presencia de las instituciones del Estado escuela, centro de salud, policía - hace parecer que se constituye una transición desde la subsunción formal a la subsunción real de la vida cotidiana al capital, en la que el campesinado anteriormente conectado al capitalismo solo a través de la venta de una porción de su producción es transformado en una fuerza de trabajo sana, educada, y disciplinada.

Sin embargo, a diferencia de Fordlandia, no hay trabajo en las Ciudades del Milenio y por consiguiente, no hay posibilidad para la subsunción real del trabajo al capital. Las entrevistas 
con funcionarios envueltos en la planificación e implementación del proyecto confirman que no hay programas de empleo ni planes productivos en las Ciudades del Milenio, y sus habitantes continúan trabajando en sus cultivos previos, que en muchos casos están a varios kilómetros de distancia (Coba, Cielo and Vallejo, 2014). No hay vías u otras infraestructuras productivas junto a las Ciudades del Milenio, a las que solo se puede acceder por río. Pañacocha está en la orilla norte del río Napo y ha sido identificada como potencial puerto del corredor Manta-Manaos, lo cual podría catalizar su urbanización (Ministerio de Relaciones Exteriores, 2010). Pero como hemos visto, el dragado del Napo es económicamente costoso y políticamente sensible, por lo que se ha frenado el desarrollo del corredor, y no se han desarrollado planes similares para Playas de Cuyabeno.

Más allá de un mecanismo para la creación de una productiva y saludable fuerza de trabajo para contribuir a la reproducción ampliada del capital, las Ciudades del Milenio podrían ser entendidas como una estrategia de acumulación por desposesión (Harvey, 2003), diseñada para obtener el consentimiento de la población indígena para la explotación de petróleo y minerales contenidos en su territorio. ${ }^{27}$ Desde esta mirada, el proyecto ha sido extremadamente exitoso. El campo petrolero de Pañacocha se encontró con una fuerte resistencia de las comunidades indígenas locales hasta el ofrecimiento de las Ciudades del Milenio y otras comunidades, previamente opuestas a la explotación petrolera, están ahora entusiasmadas por recibir una Ciudad del Milenio propia. El pueblo A’i Cofán, quien levantó una sostenida campaña contra Chevron-Texaco y después contra la empresa estatal Petroecuador, ahora ha dado el consentimiento a los proyectos petroleros en sus territorios a cambio de una Ciudad del Milenio que está actualmente en construcción. El pueblo Waorani también ha aceptado la explotación del Yasuní a cambio de una Ciudad del Milenio (El Universo, 2013b; 2013c) y otra más está en construcción en el área minera del sur. Un total de 200 han sido planeadas alrededor de las regiones ricas en recursos de la Amazonía, con la finalidad de facilitar la expansión de la frontera extractiva. ${ }^{28}$ En palabras de Correa en la inauguración de Playas de Cuyabeno, «Ahora vivir cerca de una operación petrolera es una bendición y no un castigo, como en años anteriores» (El Telégrafo, 2013c). ${ }^{29}$

Las Ciudades del Milenio prometen facilitar las operaciones de las empresas estatales de petróleo. Pero también facilitan la inversión de las empresas privadas petroleras y mineras que la administración de Correa está tratando de atraer a la región, asegurando la estabilidad política y la cohesión social requerida para la «competitividad sistémica», mientras absuelve a estas compañías de la responsabilidad de proveer inversiones sociales para las comunidades afectadas por sus operaciones (El Universo, 2013a). Como apunta Leiva (2008a) sobre la política social del neoestructuralismo, «Estas intervenciones "progresistas" construyen la hegemonía capitalista en territorios donde las políticas dogmáticas e incluso militarizadas del estado neoliberal tuvieron el acceso denegado» (p. 173). Proyectos similares han sido implementados como estrategias contrainsurgentes en áreas de conflicto en Malaya, Vietnam, Guatemala, Chiapas y otros (Wilson, 2011b); y las Ciudades del Milenio tienen su antecedente local en las reducciones coloniales y los reasentamientos del Instituto Lingüistico de Verano, que facilitaron el primer boom petrolero. Pero mientras las Ciudades del Milenio pueden tener éxito como estrategia de acumulación por desposesión, es improbable que contribuyan al desarrollo 
capitalista local a largo plazo. Hoy en día, Fordlandia está en ruinas tras su fracaso como empresa productiva (Grandin, 2009) y experimentos similares del «urbanismo rural» en Brasil en los años 70 del siglo XX, también fracasaron debido a la escasez de oportunidades de empleo. Sus habitantes regresaron a sus comunidades de origen y los nuevos centros modernos degeneraron en «favelas rurales» (Barbeiri, Monte-Mor and Bilsborrow, 2007, pp. 5-6). En suma, podemos concluir que la urbanización planetaria se extiende al corazón de la Amazonía ecuatoriana, no para integrar completamente su población dentro de la producción global de plusvalor relativo, sino solo para sacarlos fuera del camino, para que los recursos puedan ser extraídos y enviados a los circuitos que dan vida al capital como forma abstracta de dominación.

\section{CONCLUSIÓN}

Estamos ahora en disposición de revisar la teoría preliminar de la urbanización con la que comenzaba este artículo. El capital toma el proceso de trabajo como lo encuentra antes de ir transformando la materialidad de este proceso, en su camino hacia la producción de plusvalor relativo a través de la reducción del tiempo de trabajo socialmente necesario. Como parte de este proceso el capital coloniza el espacio en el que se expande, antes de producir este espacio como una máquina integrada para la producción de plusvalor relativo a través del tiempo de rotación socialmente necesario. A escala global, la urbanización planetaria es una expresión de esta transición tendencial desde la subsunción formal a la subsunción real del espacio al capital. Este proceso puede ser desagregado en al menos tres dimensiones: territorio, naturaleza y vida cotidiana. En cada caso, la misma dinámica es repetida en formas diferentes: primero el capital toma el mundo como lo encuentra y después lo transforma, de forma cada vez más intensiva, dentro de un sistema cada vez más complejo de producción de plusvalor. Este proceso, conducido por el capital, está simultáneamente fortaleciéndolo como forma abstracta de dominación. Las leyes coercitivas de la competencia fuerzan progresivamente a todos los capitalistas - y todos los estados capitalistas - a expandir incesantemente la producción de plusvalor relativo, mediante la cual emerge el capital como «un sujeto autónomo y automotriz» (Starosta, 2014, p. 299). Por ello, la urbanización planetaria puede ser entendida como un «sistema grande, complejo, dinámico y alienado, que abarca personas y máquinas, y es conducido hacia la meta de la producción por la producción» (Postone, 1993, p. 270). El capital es el sujeto de la urbanización planetaria y ambos evolucionan en un unísono dialéctico mediante la transición multidimensional de la subsunción formal a la subsunción real. Este proceso puede ser esquematizado como indica la Figura 2.

Sin embargo, mientras la transición de la subsunción formal a la subsunción real del espacio al capital es inmanente a la trayectoria de la urbanización planetaria, este proceso está continuamente debilitado por las propias contradicciones internas del capital. Las dinámicas del desarrollo geográfico desigual y la competencia interterritorial, conducen hacia la eliminación de las diferencias espaciales a través de la aniquilación del espacio por el tiempo, pero simultáneamente levantan nuevas barreras y refuerzan viejas divisiones que sabotean esta tendencia, produciendo una implacable agitación de las desigualdades sociales en lugar de una creciente igualación del mundo. En el caso de la Amazonía ecuatoriana, hemos visto 
Figura 2. El capital como sujeto de la urbanización planetaria

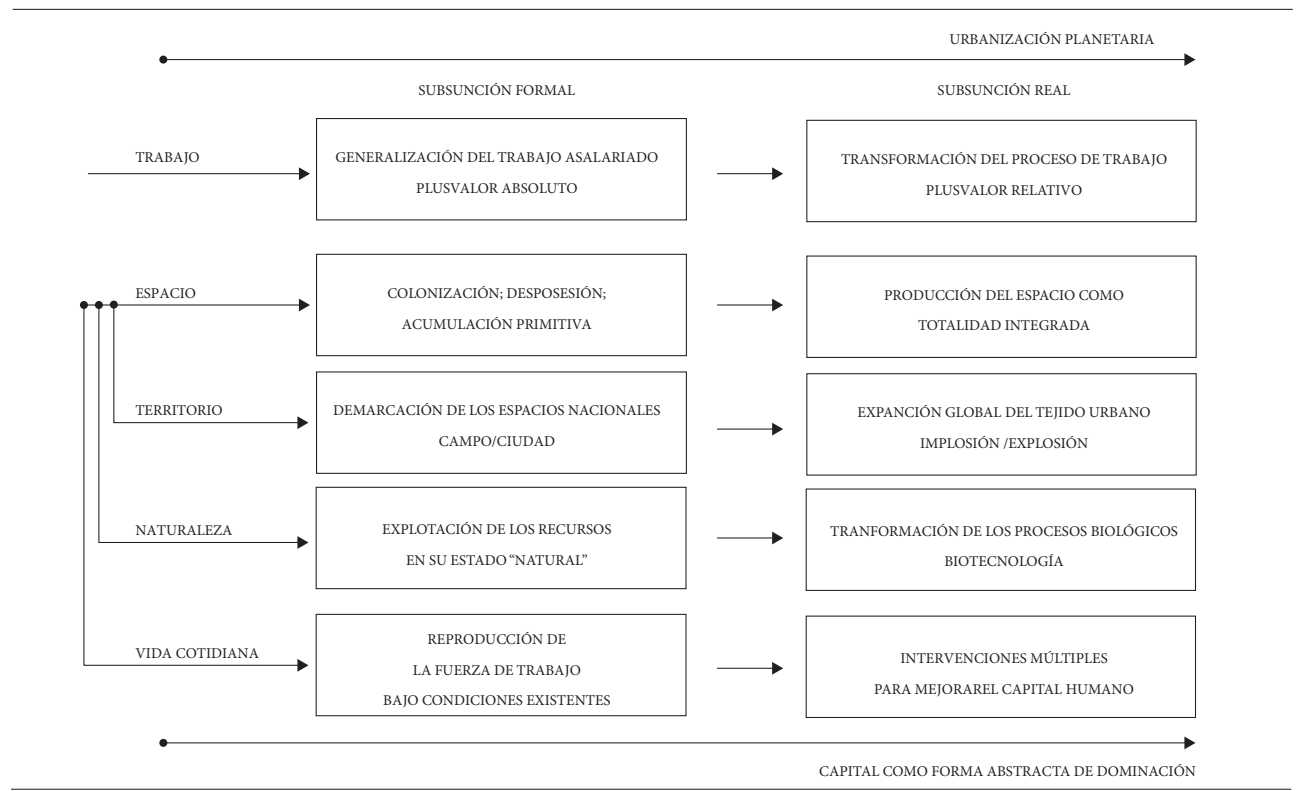

Fuente: Autores.

cómo estrategias estatales para la subsunción real de la región al capital en las dimensiones de territorio, naturaleza y vida cotidiana, están siendo obstruidas por la geografía nacional del poder de clase y la ubicación del país dentro del capitalismo global, como proveedor de materias primas que alimentan la producción de plusvalor relativo en otras partes del mundo. En cada caso, estas estrategias amenazan con reproducir los patrones existentes de subsunción formal a una escala mayor. Ello no implica que la urbanización planetaria no esté en marcha en la región. Por el contrario, estas transformaciones conllevan una mayor subordinación de la Amazonía ecuatoriana al capital como forma abstracta de dominación. Sin embargo, este proceso no debe ser entendido como una transición suave desde la subsunción formal a la subsunción real, sino como una dialéctica de subsunción formal y real, en la que la intensificación de la producción del plusvalor relativo en un lugar depende de la expansión de la frontera extractiva en otro.

Las posibilidades de un proyecto de transformación política están profundamente circunscritas por las dinámicas materiales de este proceso. En el caso del Ecuador, hemos visto cómo la administración de Correa ha buscado la «transformación de la matriz productiva», usando los recursos naturales del país para financiar vías, represas, puertos, aeropuertos, universidades y nuevos poblados, considerados necesarios para catalizar la transición desde una competitividad espuria basada en materias primas y salarios baratos, a una competitividad genuina basada en el «bioconocimiento» y la producción tecnológica. La paradoja de esta estrategia es que, mediante la subordinación de la sociedad completa a la lógica de la competitividad y la búsqueda de una «inserción inteligente» en el caldero de la 
competencia global, la administración de Correa está reforzando las presiones de la competitividad que conducen a la subsunción real del espacio al capital, mediante la cual el capital se fortalece de forma creciente como forma abstracta de dominación. Al permitir la seducción de la promesa neoestructuralista de un capitalismo sin contradicciones, en lugar de confrontar directamente la dura realidad del capital como sujeto, este proyecto «posneoliberal» está solo fortaleciendo el poder del que está supuestamente tratando de escapar. La tragedia de este proyecto es que bajo estas condiciones la competitividad solo puede lograrse mediante la intensificación de la extracción de materias primas con catastróficas consecuencias sociales y ecológicas.

Las contradicciones internas del capitalismo implican que la urbanización planetaria permanecerá como proceso de destrucción creativa que devasta lo que ha conseguido, destruyendo y aplastando vastas extensiones de la Tierra con el fin de incrementar espectaculares concentraciones de riqueza, mientras se intensifican los procesos de subsunción real mediante la cual «la ley del valor finalmente llega a ser el dictador absoluto de nuestras vidas» (Harvey, 1982, p. 153). Pero la urbanización planetaria es también un horizonte: la posibilidad de un mundo realmente unificado. La lucha inmensa e imposible, como pudiera parecer, no es contra la urbanización planetaria, sino contra el capital como forma abstracta de dominación, que es solo una forma alienada del poder creativo de la humanidad. No hay soluciones fáciles. Pero el camino debe extenderse, no en la búsqueda quijotesca de la competitividad sistémica, ni en un rechazo conservador de la urbanización, sino más bien en la apropiación de lo planetario como una posibilidad de emancipación, a la vez abierta y bloqueada por la forma alienada de nuestra propia actividad productiva.

\section{NOTAS}

1 Esta investigación finalizó en marzo de 2015.

2 Fredric Jameson (1991) construye un argumento similar respecto a las fantasías ciberespaciales de «lo sublime post-moderno»: «la tecnología de nuestra sociedad contemporánea no es fascinante e hipnótica por su propio poder, sino a causa de que parece ofrecernos un esquema de representación privilegiado a la hora de captar [...] la totalidad imposible del sistema mundial contemporáneo. Así pues, en mi opinión, lo sublime posmoderno solo puede comprenderse en términos de esta nueva realidad [...] una realidad inmensa, amenazadora, y solo oscuramente perceptible» (pp. 85-86).

3 «Ésta es probablemente la idea más importante de la crítica de la economía política marxiana plenamente desarrollada [...] el descubrimiento de la constitución social del capital como sujeto autónomo que se pone por sí mismo en movimiento, lo cual no es más que la concreción de la explicación del joven Marx respecto del trabajo enajenado» (Starosta 2014, p. 299).

4 «Del mismo modo que se puede considerar la producción de la plusvalor absoluto como expresión material de la subsunción formal del trabajo en el capital, la producción de la plusvalor relativo puédese estimar como la de la subsunción real del trabajo en el capital» (Marx, 1971, p. 60).

5 «La producción por la producción - la producción como fin en sí misma- ya entra en escena con la subsunción formal del trabajo al capital [...] Con todo, esta tendencia inmanente de la relación capitalista no se realiza de manera adecuada [...] hasta tanto no se haya desarrollado el modo de producción específicamente capitalista, y con él, la subsunción real del trabajo en el capital» (Marx, 1971, p. 75). 6 La IIRSA incluye 583 proyectos con un coste de 158 miles de millones de dólares. El 88,2\% de estos proyectos están relacionados con infraestructuras de transporte y el 10,1\% a infraestructura energética. 
El resto de proyectos están vinculados a la mejora de los pasos fronterizos y las infraestructuras de transporte (COSIPLAN, 2013, pp. 11-12). Estos proyectos están financiados por los propios estados, y también por el Banco Interamericano de Desarrollo (BID), Corporación Andina de Fonmento (CAF) y el Banco Nacional de Desarrollo Económico y Social (BNDES), empresa pública federal brasileña (Sanahuja 2012, p. 15).

7 La IIRSA fue originalmente concebida por el BID en conjunción con el Plan Puebla Panamá —un programa similar de desarrollo regional para el sur de México y Centroamérica (Wilson, 2011a). La fundación inicial de UNASUR fue expuesta en 1993, con la propuesta brasileña del Área de Libre Comercio de Sudamérica (ALCSA). Esta agenda fue confirmada en la primera Cumbre Sudamericana, realizada en Brasilia en el año 2000, cuando el IIRSA fue lanzado. En 2004, el precedente a UNASUR, la Comunidad Sudamericana de Naciones (CSN) fue creada en la tercera Cumbre Sudamericana en Cusco, Perú. La CSN buscó reforzar la IIRSA consolidando el ALCSA a través de la integración con Mercosur y la Comunidad Andina de Naciones (CAN). UNASUR incorporó estos elementos en su proyecto regional "posneoliberal» basado en una visión de desarrollo más holística (Colombo and Roark, 2012; Lockhart, 2013; Sanahuja, 2012).

8 La administración de Correa está dominada por académicos y tecnócratas (De la Torre, 2013), muchos de los cuales tienen formación neoestructuralista. El mismo Correa es doctor en economía, se identifica como «neoestructuralista» y ha publicado un working paper para la CEPAL (Correa, 2002). La administración mantiene estrechos vínculos con CEPAL, y colabora cercanamente con la institución en la formulación de los últimos planes de desarrollo. El plan fue respaldado por la Secretaría Ejecutiva de la CEPAL, Alicia Bárcenas (SENPLADES 2014, p. 45) y es completamente coherente con la última iteración del proyecto neoestructuralista (CEPAL, 2012).

9 Un documento para la atracción de inversiones elaborado por el Ministerio Coordinador de la Producción, Empleo y Competitividad (MCPEC) incluye la siguiente cita de Correa, que clarifica las bases neoestructuralistas del plan de desarrollo del gobierno: «Para que haya inversión privada debe haber buenas carreteras, energía eléctrica, puertos y aeropuertos eficientes, telefonía de punta; educación y salud de calidad, gobierno en línea con mínimos trámites, y eso es precisamente lo que estamos haciendo, eso se llama competitividad sistémica» (Rafael Correa citado en MCPEC 2011, p. 13). 10 Ecuador está envuelto en dos de los diez ejes de integración del IIRSA: el Eje Andino, que se prolonga por la cordillera de los Andes, al que pertenecen también Venezuela, Colombia, Perú y Bolivia; y el Eje Amazónico, que incluye a Colombia, Perú y Brasil, y que contempla la apertura de una serie de corredores interoceánicos entre las costas del Pacífico y del Atlántico (COSIPLAN, 2013).

11 No solo las misiones promovieron este proceso. Luego del declive del caucho varios de los trabajadores esclavizados fueron abandonados por los patrones en la zona y decidieron conformar asentamientos (agradecemos a David Chávez por esta observación).

12 El Instituto Lingüístico de Verano relocalizó distintos grupos indígenas en distintos poblados. Los A'i Cofán en Dureno, Siona y Secoya en San Pablo y Waorani en Tiweno. En el caso de los Waorani, el primer contacto fue establecido en 1956 y su relocalización en Tiweno fue forzada a través de la violencia (Almeida y Proaño 2008, p. 32).

13 Este proceso de colonización fue dirigido por el Instituto Ecuatoriano de Reforma Agraria y Colonización (IERAC), que declaró la tierra de los asentamientos colonos como «terrenos baldíos», y organizó cooperativas en las que la tierra era oficialmente distribuida a los colonos. Las cooperativas estaban integradas a la economía regional agraria, lo que incluía los remanentes de las haciendas, la producción agroindustrial de palma africana y otros cultivos de exportación (Carrión y Cuvi, 1985). 14 Los planes nacionales de desarrollo han identificado la necesidad de «Consolidar una planificación integral de la Amazonía» (SENPLADES, 2014, p. 70; ver también SENPLADES, 2009, p. 9). El gobierno ahora reclama que la Amazonía es la región que más se ha beneficiado de sus políticas de desarrollo (El Telégrafo, 2014a). En palabras de Correa «en la Amazonía tenemos carreteras, infraestructura deportiva, hospitales y escuelas del milenio. Hay una transformación radical en nuestra Amazonía» (citado en El Comercio, 2012b). 
15 Como Roberto Monte-Mor (2014) ha apuntado para el caso de Brasil, «la urbanización extendida se mueve así a través de los corredores de transporte y las redes de comunicación en "nuevas" regiones como la Amazonía» (p. 267).

16 La ruta norte por el Putumayo continúa siendo inviable debido a la presencia en la región de las Fuerzas Armadas Revolucionarias de Colombia (FARC). La ruta sur por el Morona-Marañón está también inactiva hasta este momento. Sin embargo, los proyectos de minería a gran escala están siendo promovidos en la región, y el gobierno ha comenzado a ejecutar recientemente el eje del Morona, que incluye en Ecuador puertos, vías y centrales hidroeléctricas (El Telégrafo, 2012b; COSPIPLAN, 2013, p. 85). Las dos otras rutas interoceánicas del Eje Amazonas pasan por Perú.

17 Las áreas de libre comercio en Ecuador son llamadas Zonas Especiales de Desarrollo Económico (ZEDES). Los incentivos incluyen la reducción tributaria desde el 22 al 17\%, 0\% en la tasa de Valor Añadido sobre la importación de bienes de capital y materias primas, exención de la tasa sobre transacciones financieras y pagos al exterior, y una deducción adicional del 100\% en el impuesto para la renta para los primeros cinco años de los gastos incurridos en salarios y beneficios sociales (SENECYT, 2013).

18 Por ejemplo, en 2012, la multinacional electrónica de Corea del Sur LG envió una delegación a Manta para explorar la posibilidad de enviar 3000 contenedores por año a Manaos por el corredor MantaManaos. Los contenedores serían llenados con componentes para televisores de plasma (El Telégrafo, 2012a).

19 China es actualmente el mayor socio comercial, y Brasil, con su hegemonía regional, es el principal promotor y beneficiario de la IIRSA (Sanahuja 2012, p. 10, 24).

20 En 2011, en un evento político fuertemente publicitado, el primer barco que transportaba productos ecuatorianos a lo largo de corredor Manta-Manaos hasta Brasil partió desde el puerto de Itaya (Providencia no había sido construido). Sin embargo, antes de dejar el territorio ecuatoriano, encalló en un banco de arena y estuvo varado cinco días en dicho lugar (El Comercio, 2011).

21 La biodiversidad se identifica como la mayor «ventaja comparativa» del país (SENPLADES 2009, p. 56), y «los productos que se generan a partir de información biológica y genética se diversifican y aportan significativamente a las exportaciones del país (bioprospección, bioproducción y biocomercio)» (SENPLADES, 2014, p. 42).

22 En este contexto, los beneficios para la economía nacional estarán determinados por el régimen de propiedad intelectual que establezca el gobierno (Boyd, Prudham and Schurman, 2008, p. 22). El gobierno está comprometido en asegurar que Ikiam no esté simplemente al servicio de «las necesidades de acumulación de las grandes empresas y trasnacionales» (Rene Ramírez, citado en El Telégrafo, 2013f). Pero la necesidad de atraer inversión extranjera bajo las condiciones de la competitividad global necesariamente implica que las restricciones legislativas caben dentro de parámetros aceptables para las empresas de biotecnología.

23 Como Fernando Coronil ha apuntado con su mirada de las «sociedades exportadoras de la naturaleza» como Ecuador: "paradójicamente, persiguiendo sus ventajas comparativas, estas naciones exportadoras de la naturaleza son frecuentemente reestructuradas en sus viejos roles coloniales como fuente de materias primas, un rol ahora descrito para ellas en términos de la racionalidad neoliberal del capitalismo globalizador» (Coronil, 1997, p. 7).

24 Bajo la Ley de Hidrocarburos de Ecuador de 2010, el 12\% de las regalías de cada barril de petróleo extraído de la Amazonía están destinadas a la inversión social en la región (del 15\% que habían sido previamente repartido a los trabajadores). Estos recursos debían ser distribuidos a los Gobiernos Autónomos Descentralizados (GAD) de la región. Sin embargo, en 2011 en un decreto ejecutivo se redirigían a Ecuador Estratégico, una nueva empresa pública con la responsabilidad de planear e implementar proyectos de desarrollo en las «zonas de influencia» de los "proyectos estratégicos», lo que incluye minas y campos petroleros (El Universo, 2013c). En el mismo año, se anunció que las Ciudades del Milenio serían financiadas e implementadas por Ecuador Estratégico (El Comercio, 2012a).

25 El campo de petróleo de Pañacocha está entre los ríos Napo y Aguarico. Su petróleo es bombeado bajo el Napo al centro de tratado de Edén. Pañacocha fue abierto en 2010, y fue explotado por la empre- 
sa estatal petrolera Petroamazonas. Se estima que contiene 42 millones de barriles de crudo, que serán extraídos en una tasa de entre 13000 y 25000 barriles al día (El Universo, 2010). Durante su discurso en la apertura de Pañacocha, Correa proclamó que «Este nuevo campo constituye el inicio de una nueva era petrolera, en la cual el petróleo no debe ser una maldición, sino una suerte que podrá sacarnos del subdesarrollo» (El Universo, 2010).

${ }^{26}$ Los visitantes a las Ciudades del Milenio también experimentan una sensación de asombro. En el informe de una visita a Pañacocha, por ejemplo, un periodista describe cómo «En medio de la verde selva, en las riberas del Río Napo [...] parecería que una gran urbe se colocara en el bosque» (El Telégrafo, 2013a). La apariencia mágica de las Ciudades del Milenio es similar a los proyectos de desarrollo del estado venezolano descrito por Fernando Coronil: «el petróleo es fantástico e induce fantasías [...] por los deslumbrantes y productivos proyectos de desarrollo que han engendrado fantasías colectivas del progreso, lanza sus conjuros tanto a la audiencia como a los actores» (Coronil, 1997, pp. 2, 5). Mientras acordamos con Coronil respecto a la dimensión fantasmagórica de estos proyectos, argumentamos que el encantamiento del petróleo es una representación sublime del capital como forma abstracta de dominación.

27 Desde esta mirada, es interesante apuntar las tesis del Ministro de Trabajo Carlos Marx Carrasco, quien recientemente ha tratado de justificar la intensificación de la explotación de las materias primas en términos de «la acumulación originaria del socialismo del siglo XXI», que supuestamente difiere de la acumulación primitiva del capital en la explotación de recursos naturales en lugar del trabajo humano (Marx Carrasco, 2014a; 2014b). Esto es acertado en la medida de que no hay trabajo en las Ciudades del Milenio. Pero se olvida notar el proceso de desposesión a través del cual estos recursos están abiertos a la explotación.

28 La primera Ciudad del Milenio del sur de la Amazonía será San Miguel de Conchay, uno de 106 proyectos recientemente anunciados por Ecuador Estratégico para la provincia de Morona (El Telégrafo, 2014c). Morona es uno de los potenciales centros mineros del país, y donde la minera de cobre china El Mirador comenzará pronto su producción. El puerto de Morona también es uno de los proyectos ancla de la IIRSA.

29 Las Ciudades del Milenio pueden ser interpretadas como un intento para ocultar las consecuencias ecológicas de la dependencia a la explotación petrolera bajo una fantasía de modernidad. En julio de 2014, sin embargo, Playas de Cuyabeno experimentó un «retorno de lo reprimido» cuando un deslizamiento rompió el oleoducto Sucumbíos-Lago Agrio, con el resultado de un vertido de aproximadamente 2000 barriles de petróleo. Parte de ello llegó al río Aguarico y fue recogido aguas debajo de Playas de Cuyabeno (situado en la orilla sur del río Aguarico), contaminando el suministro local de agua (El Comercio, 2014d).

\section{AGRADECIMIENTOS}

Gracias a Lucas Álvarez, Îñigo Arrazola, Omar Bonilla, Greig Charnock, David Chávez, Nora Fernández, David Harvey, Pablo Iturralde, Tania Macera, Tom Purcell, Miguel Robles-Duran, Ioanna Tantanasi, Eva Vázquez; y todo el equipo del CENEDET por los comentarios sobre los borradores iniciales y sus aportes fundamentales. Los errores que aún quedan son solo nuestros.

\section{REFERENCIAS}

«Ikiam no tendrá facultades». (Entrevista, C. Ávila). (2014d, junio 25). El Telégrafo. Recuperado de http:// www. telegrafo.com.ec/sociedad/item/avila-ikiam-no-tendra-facultades.html

«La idea es ir de los recursos finitos a los infinitos». (R. Ramírez, Entrevista). (2013f, diciembre 13). El Telégrafo. Recuperado de http://www.telegrafo.com.ec/cultura1/item/la-idea-es-ir-de-los-recursos-finitos-a-los-infinitos. html 
10 comunidades no tienen agua por el derrame petrolero. (2014d, julio 4). El Comercio. Recuperado de http://www. elcomercio.com.ec/actualidad/sucumbios-derrame-crudo-agua-contaminacion.html 500 toneladas se exportaron hacia Brasil por el Napo. (2011, julio 17). El Comercio. Recuperado de http:// www. elcomercio.com/actualidad/negocios/500-toneladas-se-exportaron-hacia.html

Acosta, A. (2013). A modo de prologo: El correísmo, un nuevo modelo de dominación burguesa. En A. Acosta (Ed.) El correismo al desnudo (pp. 9-21). Quito, Ecuador: Arcoiris.

Aguirre, M. (2010). ¿Golpe de timón en Ecuador? El viejo topo, 270-271, 48-57.

Alianza País (2006). Plan de Gobierno del Movimiento PAIS 2007-2011 Quito, Ecuador: Alianza País.

Almeida, A. y Proaño, J. (2008). Tigre, águila y waorani. Una sola lucha, una sola selva. Quito, Ecuador: Acción Ecológica.

Arsel, M. (2012). Between Marx and Markets? The State, the 'Left Turn' and Nature in Ecuador. Tijdschrift voor Economische en Sociale Geografie, 103(2), 150-163.

Autoridad Portuaria de Manta (2006). Eje Multimodal Pacífico-Atlántico Ecuador-Brasil. PowerPoint presentation.

Barbieri, A., Monte-Mór, R. and Bilsborrow, R. E. (2007, junio). Towns in the jungle: exploring linkages between rural-urban mobility, urbanization and development in the Amazon. Paper presented to the PRIPODE workshop on Urban Population, Development and Environmental Dynamics in Developing Countries. Nairobi, Kenya.

Bayón, M. (2013, diciembre 12). La urbanización de la Amazonía como estrategia continua de la acumulación por despojo capitalista-extractiva. La Ciudad Viva. Recuperado de http://www. laciudadviva.org/blogs/?p=20229

Becker, M. (2011). ¡Pachakutik! Indigenous Movements and Electoral Politics in Ecuador. Plymouth, EE.UU.: Rowman and Littlefield Publishers, Inc.

Becker, M. (2013a). The Stormy Relations between Rafael Correa and Social Movements in Ecuador. Latin American Perspectives, (40), 43-62.

Becker, M. (2013b). Ecuador's Buen Vivir Socialism. En R. Burbach, M. Fox and F. Fuentes, Latin America's Turbulent Transitions: The Future of Twenty-First Century Socialism (pp. 98-113). London, UK: Zed.

Boyd, W., Prudham, S. and Schurman R. (2008, Julio 21). Industrial Dynamics and the Problem of Nature. Geography \& Planning. University of Toronto. Recuperado de http://geography.utoronto.ca/ wp-content/ uploads/2013/10/SNR2001final.pdf

Brenner, N. (2013). Tesis sobre la urbanización planetaria. Nueva Sociedad, (243), 38-66.

Brenner, N. (2014a). Introduction: Urban Theory without an Outside. En N. Brenner (Ed.), Implosions/ Explosions: Towards a Study of Planetary Urbanization (pp. 14-35). Berlin, Germany: Jovis.

Brenner, N. (2014b). Theses on Urbanization. En N. Brenner (Ed.) Implosions/Explosions: Towards a Study of Planetary Urbanization (pp.181-202). Berlin, Germany: Jovis.

Brenner, N. and Schmid, Ch. (2014). Planetary Urbanization. En N. Brenner (Ed.) Implosions/Explosions: Towards a Study of Planetary Urbanization (pp. 160-163). Berlin, Germany: Jovis.

Bryan, J. (2012). Rethinking Territory: Social Justice and Neoliberalism in Latin America's Territorial Turn. Geography Compass 6(4), 215-226.

Carrión, L. y Cuvi, M. (1985). La palma africana en el Ecuador: tecnología y expansión empresarial. Quito, Ecuador: FLACSO. 
CDES (2011). Estado de situación de los derechos humanos en la Amazonía ecuatoriana y criterios para la construcción de una agenda regional. (Artículo no publicado).

CEPAL (2012). Cambio Estructural para la Igualdad: Una visión integrada del desarrollo. Santiago, Chile: ECLAC

Chávez, D. (2013, diciembre). El estado del debate sobre desarrollo, extractivismo y acumulación de capital en el Ecuador. CENEDET. Recuperado de https://derechoterritorio.files.wordpress.com /2014/09/chavez_debate_desarrollo-extractivismo.pdf

Cipolletti, M. S. (1988). Aipe Koka. Quito, Ecuador: Abya Yala.

Ciudad del Milenio emerge de la selva. (2013a, septiembre 5). El Telégrafo. Recuperado de http://www. telegrafo. com.ec/economia/item/ciudad-del-milenio-emerge-de-la-selva.html

Coba, L., Cielo, C. and Vallejo, I. (2014). Women, Nature and Development in Sites of Ecuador's Petroleum Circuit. (Unpublished draft manuscript).

Colombo, S. and Roark, M. (2012). UNASUR: integración regional y gobernabilidad en el siglo XXI. Densidades, (10), 21-40.

Comuneros tendrán casas equipadas con tecnología de punta. (2013b, octubre 1). El Telégrafo. Recuperado de http://www.telegrafo.com.ec/noticias/informacion-general/item/comunerostendran-casas-equipadas-con-tecnologia-de-punta.html

Comunidades del milenio se replicarán en toda la Amazonia con rentas petroleras, según gobierno. (2014, enero 16). El Universo. Recuperado de http://www.eluniverso.com/noticias/2014/01/16/ nota/2039856/comunidades-milenio-se-replicaran-toda-amazonia-rentas-petroleras

Coronil, F. (1997). The Magical State: Nature, Money and Modernity in Venezuela. Chicago, EE.UU.: University of Chicago Press.

Correa, R. (2002). Reformas estructurales y crecimiento en América Latina: un análisis de sensibilidad. Revista de la CEPAL, (76), 89-107.

COSIPLAN (2013). Cartera de Proyectos. IIRSA. Recuperado de http://www.iirsa.org/Document/ Detail? Id $=3716$

Cuyabeno tiene su primera Ciudad del Milenio con excedentes petroleros. (2013c, octubre 1). El Telégrafo. Recuperado de http://www.telegrafo.com.ec/noticias/informacion-general/item/ cuyabeno-tiene-su-primera-ciudad-del-milenio-con-excedentes-petroleros.html

Dávalos, P. and Albuja, V. (2014). Ecuador: Extractivist Dynamics, Politics and Discourse. En H. Veltmeyer and J. Petras (Eds.), The New Extractivism: A Post-Neoliberal Development Model or Imperialism of the Twenty-First Century? (pp. 144-171). London, UK: Zed.

De la Torre, C. (2013). El tecnopopulismo de Rafael Correa: ¿Es compatible el carisma con la tecnocracia? Latin American Research Review, 48(1), 24-43.

Deler, J. P., Gómez, N. and Portais, M. (1983). El manejo del espacio en el Ecuador. Geografía básica del Ecuador. Quito, Ecuador: IGM.

Ecuador apuesta a un radical cambio en su educación superior. (2014c, junio 25). El Comercio. Recuperado de http://www.elcomercio.com.ec/tendencias/ecuador-apuesta-radical-cambioeducacion.html

Ecuador espera integración de Venezuela a eje de vialidad con Perú y Brasil. (2012b, octubre 20). El Telégrafo. Recuperado de http://www.telegrafo.com.ec/noticias/informacion-general/item/ ecuador-espera-integracion-de-venezuela-a-eje-de-vialidad-con-peru-y-brasil.html 
Ecuador, con petróleo para 20 años más. (2012a, julio 16). El Comercio. Recuperado de http://www. elcomercio.ec/ actualidad/negocios/ecuador-petroleo-20-anos-mas.html

El Oriente vive dos realidades. (2013c, octubre 6). El Universo. Recuperado de http://www.eluniverso.com/ noticias /2013/10/06/nota/1543081/oriente-vive-dos-realidades

Enlace ciudadano N. ${ }^{\circ}$ 294. (2012b, octubre 20). El Comercio. Recuperado de http://www.elcomercio.com/ actualidad/ politica/enlace-ciudadano-no-294.html

Escribano, G. (2013). Ecuador's energy policy mix: Development versus conservation and nationalism with Chinese loans. Energy Policy, (57), 152-159.

Galarza Zavala, J. (1972). El Festín del Petróleo. Cuenca, Ecuador: Editora Sol.

García, L. (1985). Historia de las misiones en la Amazonía ecuatoriana Quito, Ecuador: Abya-Yala.

Gobierno inaugura vía que se integrará al eje Manta-Manaos. (2014a, febrero 5). El Telégrafo. Recuperado de http://www.telegrafo.com.ec/noticias/informacion-general/item/gobierno-inaugura-via-que-seintegrara-al-eje-manta-manaos.html

Gramsci, A. (1973). Selections from the Prison Notebooks. London: Lawrence and Wishart.

Gutiérrez Marín, W. (2002). Baeza Ciudad de los Quijos. Quito, Ecuador: Abya Yala.

Harvey, D. (1982). The Limits to Capital. Oxford, UK: Blackwell.

Harvey, D. (2000). Spaces of Hope. Berkeley. USA: University of California Press.

Harvey, D. (2003). The New Imperialism. Oxford, UK: Oxford University Press.

Harvey, D. (2014). Cities or Urbanization? En N. Brenner (Ed.), Implosions/Explosions: Towards a Study of Planetary Urbanization (pp. 52-66). Berlin, Germany: Jovis.

Hay temor en la ruta al Parque Nacional Yasuní. (2013a, junio 16). El Universo. Recuperado de http://www. eluniverso.com/noticias/2013/06/16/nota/1031761/hay-temor-ruta-yasuni

Ikiam fusiona construcción ancestral y tecnología. (2014b, s.f.). El Comercio. Recuperado de http://www.elcomercio. com.ec/tendencias/construir/ikiam-fusiona-construccion-ancestral-y.html

Ikiam tendrá laboratorio natural. (Infografía). (2013e, diciembre 5). El Telégrafo. Recuperado de http://www. telegrafo.com.ec/sociedad/item/ikiam-tendra-laboratorio-natural.html Ikiam

Ikiam ya instala su futuro. (2013d, diciembre 4). El Telégrafo. Recuperado de http://www.telegrafo.com.ec/ portafolio/item/ikiam-ya-instala-su-futuro-2.html

Inter-American Development Bank (2001). Summit of the Americas: Strategic Programs. Washington, USA: Inter-American Development Bank

Inter-American Development Bank (2010). Ten Years of the IDB in IIRSA: 2000-2010. Washington, USA: Inter-American Development Bank

Iturralde, P. (2013). Apuntes para Pensar la Ampliación de la Frontera Petrolera y Minera en Ecuador. En CDES, La Alquimia de la Riqueza: Estado, Petróleo, y Patrón de Acumulación en Ecuador (pp. 139176). Quito, Ecuador: CDES.

Jameson, F. (1991). El posmodernismo o la lógica cultural del capitalismo tardío. Buenos Aires, Argentina: Paidós.

Kanai, J. M. (2014). On the Peripheries of Planetary Urbanization: Globalizing Manaus and Its Expanding Impact. Environment and Planning D: Society and Space, (32), 1-17.

Kennemore, A. and Weeks, G. (2011). Twenty-First Century Socialism? The Elusive Search for a PostNeoliberal Development Model in Bolivia and Ecuador. Bulletin of Latin American Research, 30(3), pp. 267-281. 
La Universidad Ikiam conjuga la naturaleza con lo contemporáneo. (2014a, s.f.). El Comercio. Recuperado de http://www.elcomercio.com/actualidad/universidad-ikiam-conjuga-naturaleza-contemporaneo.html

Lefebvre, H. (2008). Critique of Everyday Life. Vol. 3. London, UK: Verso.

Leiva, F. I. (2008a). Latin American Neostrucuralism: The Contradictions of Post-Neoliberal Development. Minneapolis, USA: University of Minnesota Press.

Leiva, F. I. (2008b). Towards a Critique of Latin American Neostucturalism. Latin American Politics and Society 50(4), 1-25.

LG interesada en usar el puerto de Manta para llegar a Brasil. (2012a, mayo 8). El Telégrafo. Recuperado de http://www.telegrafo.com.ec/economia/item/lg-interesada-en-usar-el-puerto-de-mantapara-llegar-a-brasil.html

Maldonado, A. (2001). La forma Occidental de extraer Petróleo. Quito, Ecuador: Oilwatch.

Marx Carrasco, C. (2014a, febrero 10). La acumulación originaria del socialismo del siglo XXI (Parte 1). El Telégrafo. Recuperado de http://www.telegrafo.com.ec/economia/masqmenos/item/laacumulacion-originaria -del-socialismo-del-siglo-xxi-parte-i.html

Marx Carrasco, C. (2014b, febrero 17). La acumulación originaria del socialismo del siglo XXI (Parte 1). El Telégrafo. Recuperado de http://www.telegrafo.com.ec/economia/masqmenos/item/laacumulacion-originaria -del-socialismo-del-siglo-xxi-parte-ii.html

Marx, K. (1971). Resultados del proceso inmediato de producción. Libro I. Capítulo VI. Inédito. Madrid, España: Siglo XXI Editores.

Marx, K. (1973). Grundrisse. London, UK: Pelican

Marx, K. (1976). Capital Volume One. New York, USA: Random House.

Marx, K. y Engels, F. (2000). Manifiesto comunista. Buenos Aires, Aregentina: Ediciones Elaleph.com

Merrifield, A. (2014). The Urban Question under Planetary Urbanization. En N. Brenner (Ed.) Implosions/Explosions: Towards a Study of Planetary Urbanization (pp. 164-180). Berlin, Germany: Jovis.

Ministerio de Relaciones Exteriores (2010). Manta-Manaus: Eje Multimodal Bi-Oceánico PowerPoint presentation

Ministerio de Relaciones Exteriores (2013). Avances en la ejecución del eje Manta-Manaos. Press reléase. Recuperado de http://cancilleria.gob.ec/avances-en-la-ejecucion-del-eje-manta-manaos/

Ministerio de Transporte y Obras Públicas (2014). Vía Yamanunka - Puerto Providencia al servicio de los ecuatorianos. Press release. Recuperado de http://www.obraspublicas.gob.ec/ via-yamanunka-puerto-providencia-al-servicio-de-los-ecuatorianos/

Monte-Mór, R. L. (2014). Extended Urbanization and Settlement Patterns in Brazil: An Environmental Approach. En N. Brenner (Ed.) Implosions/Explosions: Towards a Study of Planetary Urbanization (pp. 109-120) Berlin, Germany: Jovis.

Monte-Mór, R. L. (2014). What is the Urban in the Contemporary World? En N. Brenner (Ed.) Implosions/ Explosions: Towards a Study of Planetary Urbanization (pp. 260-267). Berlin, Germany: Jovis.

Morona accede a 106 proyectos. (2014c, abril 9). El Telégrafo. Recuperado de http://www.telegrafo.com. ec/ regionales/regional-sur/item/morona-accede-a-106-proyectos.html

Muratorio, B. (1987). Rucuyaya Alonso y la historia social y económica del Alto Napo 1850-1950 Quito, Ecuador: Abya-Yala. 
Proceso de inscripción para interesados en estudiar en IKIAM. (2014b, febrero 18). El Telégrafo Recuperado de http://www.telegrafo.com.ec/sociedad/item/proceso-de-inscripcion-para-interesados-en-estudiar-en-ikiam. html

Providencia será el punto de enlace entre Manta y Manaos. (2008, marzo 28). Nuestro Mar. Recuperado de http://www.nuestromar.org/noticias/puertos_03_2008_puerto_providencia_sera_el_punto_de_ enlace_entre_manta_y_man_1500

Proyecto Manta-Manaos busca mejorar vida de comunidades. (2011, agosto 2). El Telégrafo. Recuperado de http://www.telegrafo.com.ec/noticias/informacion-general/item/proyecto-manta-manaosbusca-mejorar-vida-de-comunidades.html

Radcliffe, S. A. (2012). Development for a post-neoliberal era? Sumak kawsay, living well and the limits to decolonisation in Ecuador. Geoforum, (43), 240-249.

Ramírez, R. (2012). Socialismo del sumak kawsay o biosocialismo republicano. SENESCYT. Recuperado de http://www.educacionsuperior.gob.ec/wp-content/uploads/downloads/2013/02/ SOCIALISMO-DEL-SUMAK -KAWYSAY.pdf

Régimen arrancó oficialmente su producción en Pañacocha. (2010, octubre 22). El Universo. Recuperado de http://www.eluniverso.com/2010/10/22/1/1356/regimen-arranco-oficialmente-produccionpanacocha.html

Ruiz, M. (2013). La alquimia de la riqueza: Estado, petróleo, y patrón de acumulación en Ecuador. CDES, pp. 1-68.

Sanahuja, J. A. (2012). Post-Neoliberal Regionalism in South America: The Case of UNASUR. EUI Working Papers.

SENESCYT (2013). Yachay: City of Knowledge. Quito, Ecuador: SENESCYT.

SENPLADES (2009). Plan Nacional Para el Buen Vivir 2009-2013. Versión resumida. Quito, Ecuador: SENPLADES

SENPLADES (2014). Buen Vivir: Plan Nacional 2013-2017. Versión resumida. Quito, Ecuador: SENPLADES.

Si llegan obras, indígenas darán apoyo a explotación en el Yasuní. (2013b, octubre 3). El Universo. Recuperado de http://www.eluniverso.com/noticias/2013/10/03/nota/1531101/ si-llegan-obras-indigenas-daran-apoyo

Smith, N. (1984). Uneven Development: Nature, Capital, and the Production of Space. Oxford, UK: Blackwell.

Smith, N. (2007). Nature as Accumulation Strategy. Recuperado de http://3to1z93m5aspz1tlz1zcsjta2m. wpengine. netdna-cdn.com/goldstein2014/wp-content/uploads/sites/316/2014/08/nature-as-accumulation-strategy.pdf

Soares de Lima, M. R. (2008). El lugar de América del Sur en la política externa brasileña. Itamaraty. Recuperado de http://dc.itamaraty.gov.br/imagens-e-textos/obrasintegracao-esp02.pdf

Soja, E. W. and Kanai, M. (2014). The Urbanization of the World. En N. Brenner (Ed.), Implosions/ Explosions: Towards a Study of Planetary Urbanization (pp. 142-159). Berlin, Germany: Jovis.

Starosta, G. (2014). Marx's Capital, Method and Revolutionary Subjectivity. (Draft manuscript).

The Travails of ALBA. (2014, octubre 18). The Economist. Recuperado de http://www.economist.com/ news/ americas/21625792-more-successful-latin-americas-populists-have-become-more-pragmatic-travails-alba 
Unda, M. (2013). Modernización del capitalismo y reforma del Estado. En A. Acosta (Ed.) El correísmo al desnudo (p. 33). Quito, Ecuador: Arcoiris.

Vickers, W. T. (1989). Los Sionas y Secoyas. Quito, Ecuador: Abya Yala.

Villavicencio, A. (2013, s.f.). ¿Hacia dónde va el proyecto universitario de la revolución ciudadana? UASB. Recuperado de http://repositorio.uasb.edu.ec/bitstream/10644/3235/1/Villavicencio,\%20A-CON001-Hacia \%20donde.pdf

Walsh, C. (2010). Development as Buen Vivir: Institutional Arrangements and (De)colonial Entanglements. Development 53(1), 15-21.

Wilson, J. (2011a). Colonising Space: The New Economic Geography in Theory and Practice. New Political Economy, (16), pp. 373-397.

Wilson, J. (2011b). Notes on the Rural City: Henri Lefebvre and the Transformation of Everyday Life in Chiapas, Mexico. Environment and Planning D: Society and Space, (29), 993-1009.

Žižek, S. (2003). Sublime objeto de la ideología. Buenos Aires, Argentina: Siglo XXI. 
